\title{
Bingöl Düzağaç Kavşağının Rotor Tipi Turbo Dönel Kavşak Olarak Düzenlemesi Durumu için Kapasite Hesaplarının Ön Çalışması
}

\author{
İhsan GÜZEL ${ }^{1 *}$ \\ ${ }^{1}$ İnşaat Mühendisliği Bölümü, Mühendislik ve Mimarlık Fakültesi, Bingöl Üniversitesi, Bingöl, Türkiye \\ *1 iguzel@bingol.edu.tr
}

(Geliş/Received: 04/02/2020;

Kabul/Accepted: 06/10/2020)

Öz: Çok şeritli dönel kavşakların alternatif bir formu olan turbo dönel kavşaklar, kapasite ve güvenliğinin çok şeritli dönel kavşaklara göre avantajlarından dolayı son yıllarda birçok ülkede tasarım rehberleri hazırlanarak uygulamalarına başlanılmıştır. Bu çalışmada turbo kavşakların güvenlik ve kapasite üstünlükleri göz önüne alınarak Bingöl Düzağaç mevkiinde bulunan sinyalizasyonlu ana yol, tali yol kavşağında, yol kullanıcısı ve taşıt işletme maliyetlerinin azaltılması için turbo dönel kavşak olarak düzenleme ön çalışması yapılmıştır. Bu kavşakta belirlenen senaryoya göre devlet yolunda trafik akımının alt geçitli veya alt geçitsiz sağlanması durumunda rotor tipi turbo kavşakların sinyalizasyonuz uygulanması için kapasite hesaplanmıştır. Alt geçitli turbo kavşağın alt geçitsiz turbo kavşağa göre kavşak kollarının şerit doygunluk yüzdelerinde ortalama 4 kat azalma olmasına rağmen; ana konumda bulunan Bingöl Sanayi ve tali konumda bulunan Bingöl Şehir Merkezi kollarında trafik artışı olması durumunda sola dönüşlerin üst geçitle sağlanması gerekeceği tespit edilmiştir.

Anahtar kelimeler: Turbo Kavşak, Kapasite, Altgeçit, Şerit, Doygunluk, Trafik Senaryosu.

\section{Preliminary Study of Capacity Calculations for Regulation as Rotor Type Turbo Roundabout Status of Bingol Duzagac Junction}

\begin{abstract}
An alternative form of multi-lane roundabouts, turbo roundabouts; Due to the advantages of its capacity and safety compared to multi-lane roundabouts, design guides have been prepared and started to be implemented in many countries in recent years. In this study, a preliminary study was made for the turbo roundabouts in order to reduce road user and vehicle operating costs at the signaling main road secondary road junction in Bingol Duzagac location considering the safety and capacity advantages. According to the scenario determined at this intersection, capacity is calculated for the implementation of rotor type turbo junctions without signaling in case the traffic flow on the state road is provided with or without an underpass. Although there is an average 4 fold reduction in the strip saturation percentages of the junction arms of the underpass turbo junction compared to the turbo junction without underpass; It is determined that if there is an increase in traffic in the branches of 'Bingol Industrial Site' located in the main location and 'Bingol City Center' located in the secondary location, left turns will need to be provided by overpass.
\end{abstract}

Key words: Turbo Junction, Capacity, Underpass, Lane, Saturation, Traffic Scenario

\section{Giriş}

Karayollarının kesişmesi, birleşmesi ve ayrılmasıyla teşekkül edilen kavşak alanları, karayolunun hız, işletme, kapasite, maliyet ve güvenlik faktörlerini etkilemektedir. Kavşaklar güvenlik, estetik, hizmet seviyesi ve ekonomiklik prensipleri gözönüne alınarak; sürekliğin sağlanması, güvenliğin ve hızın artırılması, yeterli hizmet seviyesinin sağlanması, taşıt işletme maliyetlerinin azaltılması amacıyla sistem ve servis formunda eş düzey, farklı düzey ve seviye ayrımlı tiplerinde yapılmaktadır [1,2].

Kavşaklar çakışmaları azaltmak, kapasiteyi artırmak ve rahat manevra yapılmasını sağlayacak temel hedefler göz önünde bulundurularak; toplanan bölgesel ve trafik verilerine göre insan, trafik, güvenlik, ekonomiklik, kavşak alanlarının fonksiyonellik ve fiziksel faktörleriyle beraber; algı, manevra, kuyruk mesafesi unsurları dikkate alınarak tasarlanmaktadır [3].

Kavşaklarda kesişme kontrolleri pasif, aktif ve kısmi kontrol seviyeleriyle yapılmakta olup; pasif kontrol trafik hacminin az olduğu kavşaklarda yol kullanıcılarının temel kurallara uyması koşuluyla kontrollerin düşey veya yatay işaretlemelerle, aktif kontroller sinyalizasyon ve farklı seviyeli geçişlerle, kısmi kontrol ise kanalize ayrımları ve dairesel adalarla sağlanmaktadır [4].

Trafik akımının merkezi bir ada etrafında yönlendirildiği ve ada etrafında araçların ilk geçiş hakkına sahip olduğu işaretlerle belirtilerek; kesişmelerin kısmı kontrolle önlenmeye çalışıldığı modern dönel kavşaklarda, yakıt

\footnotetext{
* Sorumlu yazar: iguzel@,bingol.edu.tr. Yazarın ORCID Numarası: 0000-0002-9368-8902
} 
tüketimi hava kirliliği, durma gecikme süreleri ve kaza sayılarında ortalama olarak $\% 40$ oranında azalmaktadır $[5,6]$.

Kapasite ve güvenlik avantajları nedeniyle modern dönel kavşakların alternatif olarak düşünülen turbo kavşaklarla ilgili yapılan bazı çalışmalara ait sonuçlar aşağıda açıklanmıştır.

Vincenzo, dönel kavşağa giren iki kolun girişi iki, çıkışları tek ve diğer kollarının giriş çıkışları tek şeritli olan mevcut iki şeritli sıkıştırılmış dönel kavşağın performansının artııılması için kollarının giriş çıkışları iki şeritli olan turbo dönel kavşağa dönüştürülmesi çalışmasında; trafik akımının fazla olduğu kollarda kapasitenin ortalama \%40 arttı̆̆ıııı, simülasyon çalışmasında ise kuyruk boyunun\%90 oranında azaldığını belirlemiştir [7].

Pitlova, giriş ve çıkışları tek şeritli olan dört kollu mevcut dönel kavşağın turbo kavşak tiplerine dönüştürülmesi halinde, teorik olarak hesapladığı kapasite analizlerine göre turbo kavşaklarda taşıtların bekleme süresi 10 kat azalmıştır [8].

Skavania, Çek Cumhuriyetinde çeşitli tiplerde yapılan turbo kavşak kapasitelerinin, kavşak kollarının giriş çıkış şerit sayılarına ve kollarda trafik akım özelliklerine göre değişmekle beraber 2700 taşıt/saat ile 3800 taşıt/saat arasında olduğunu; ayrıca milyon taşıt başına kaza sayısının ortalama \%60 azalma olduğunu belirtmiştir [9].

Babokic, Zagreb’te bulunan dört kollu sinyalizasyonlu bir kavşağın dönel ve turbo kavşak olarak düzenlemesi durumunda, mikro simülasyon yöntemleriyle yaptığı hesaplamalar sonucunda, turbo kavşak kollarında elde edilen kuyruk uzunluğu, taşıt gecikmesi, seyahat süresi ve emisyon yayılımı önemli oranda azaldığı görülmüştür [10].

Silva, Portekiz’in Lizbon şehrinde iki kolunun giriş kapasitesi yüksek olan mevcut bir dönel kavşağın, turbo kavşak yapılması durumunda, bu kollarda kapasitesinin ortalama \%20 düşeceği hesaplamış; ayrıca türbo kavşakların aynı boyutta dönel kavşaklara göre kapasitesinin bir miktar az olacağını belirtmiş̧tir $[11,12]$.

Izadi, pik saatte dört kolunun her birimde trafik hacmi 1000 taşııın üzerinde olan dönel kavşakla, turbo dönel kavşağı trafik performansı açısından karşılaştırma çalışmasında; turbo kavşakta seyahat, durma gecikme sürelerinin ve kuyruk uzunluğunun azaldığını göstermiştir [13].

Guerrieri ve Corriere, merkez ada etrafında şerit sayıları ve kollara giriş çıkış şerit sayıları iki olan dönel kavşakla turbo dönel kavşağı günlük kapasiteleri karşılaştırmış; turbo kavşakların yaklaşık olarak \%20 oranında günlük kapasitesinin fazla olduğu belirlemiştir [14].

Turbo kavşakların yukarıda belirtilen olumlu sonuçlar göz önünde bulundurularak; Bingöl ilinin yerleşim alanından batı doğu yönünde geçen $6,80 \mathrm{~km}$ devlet yolu (Elazığ-Muş) üzerinde bulunan mevcut aktif kontrollü altı kavşaktan, yıllık ortalama günlük trafiği (YOGT) en yüksek olan Düzağaç kavşağının sinyalizasyon nedeniyle oluşan taşıt işletme maliyetlerinin azaltılması için literatür incelemelerinde ülkenizde uygulaması olmayan turbo kavşak olarak düzenlenmesinin araştırılmasının önemli olduğu düşünülerek bu çalışma yapılmıştır.

\section{Turbo Kavşak}

Geçmişte uygulanması zorunlu olan dönel kavşak koşullarının değişmesi ve bu kavşakların kısmı dezavantajları nedeniyle son zamanlarda belli ülkelerde iki şeritli dönel kavşakların yenilikçi bir düzenlemesi olan turbo dönel kavşak uygulamalarına başlanılmıştır. Turbo kavşaklar giriş veya çıkış kollarında trafik hacmine göre merkezi ada çapının değiştirilmesiyle elde edilen spirallerin belirli yön akışlarının şeritler boyunca fiziksel olarak ayrıldığı ve dönel kavşakların şiddetli çakışma noktalarının bazılarını kaldırarak trafik akışının sağlandığı çok şeritli dönel kavşak türüdür $[15,16]$.

Hollanda'nın Delft Üniversitesi araştırmacısı Dr. Lambertus Fortuijn tarafından 1998 yılında geliştirilen turbo dönel kavşaklar, yapılan analizler sonucunda 2008 yılında ilk olarak Hollanda'da tasarım rehberi hazırlanmıştır. Almanya gibi gelişmiş ülkelerin de yer aldığı bazı ülkeler tasarım rehberleri yayınlamış olup; Amerika'da ise araştırmalar devam etmektedir. Yayınlanan rehberlerde geometrik tasarım;

-Mevcut kavşak türlerinden birini seçmek

-Tasarım aracinı tanımlama,

-Turba Blok Şablonunu belirlemek,

-Turbo kavşağın diğer elemanlarının tasarımı aşamalarından

-Tasarım araçlarının yatay süpürme ve hız analizi aşamalarıyla yapılmaktadır.

Turbo dönel kavşakların üç kollu ve dört kollu tiplerinde (Şekil 1-2) egg, basic turbo, knee, spiral ve stretchedknee formları kollarda trafik akışı̧̧larından birinin fazla olduğu durumlarda, rotar ve star formları ise kollarda trafik akışının yakın olduğu durumlarda önerilmektedir [17]. 


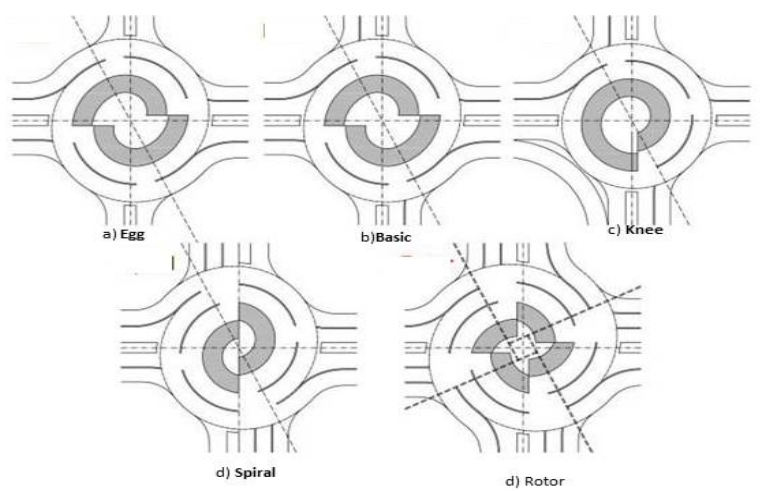

Şekil 1. Dört kollu kavşak formları[17]
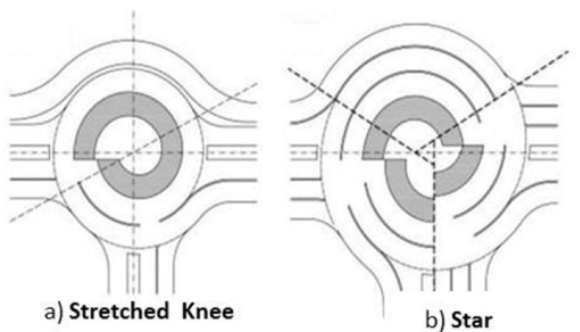

Şekil 2. Üç kollu kavşak formları[17]

Tasarımın en önemli elemanlarından olan iç-dış daire yarıçapları, şerit genişlikleri, iç-dış merkezler arasında farklar ve en kesit Şekil 3,4'de, bu elemanların geniş ve mini turbo kavşaklar için Hollanda'ya ait değerleri ise Tablo 1'de gösterilmiş̧ir. Bu değerlere göre geniş bir turbo kavşak için tasarım şartlarını sağlanması koşuluyla, geniş turbo kavşaklar için yaklaşık $3000 \mathrm{~m}^{2}$, küçük turbo kavşaklar için ise $1500 \mathrm{~m}^{2}$ alan gerekmektedir.

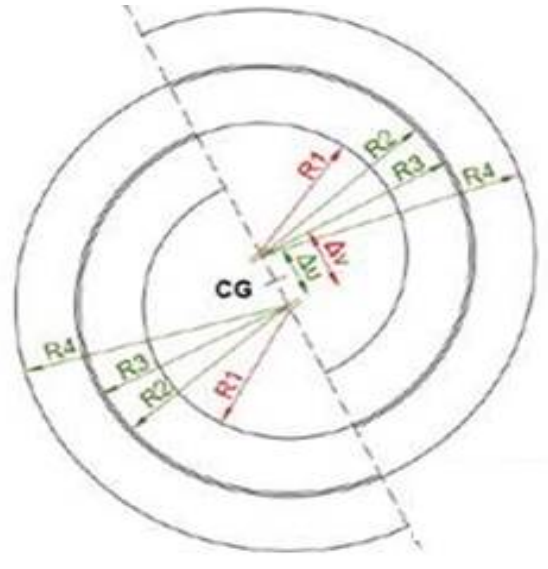

Şekil 3. Turbo kavşak blok elemanları[17] 


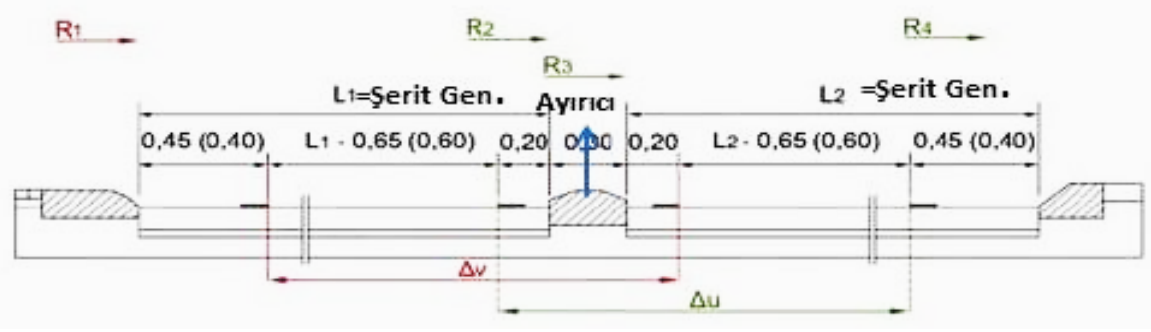

Şekil 4. Turbo Kavşak en kesiti[17]

Tablo 1. Turno kavşak yatay eksen elaman boyutları[17]

\begin{tabular}{|c|c|c|}
\hline \multirow{2}{*}{ Kavşak Elemanı } & \multicolumn{2}{|c|}{ Turbo Kavşak Tipi } \\
\cline { 2 - 3 } & Mini & Geniş \\
\hline $\mathrm{R}_{1}(\mathrm{~m})$ & 10,50 & 20,00 \\
$\mathrm{R}_{2}(\mathrm{~m})$ & 15,85 & 24,90 \\
$\mathrm{R}_{3}(\mathrm{~m})$ & 16,15 & 25,20 \\
$\mathrm{R} 4(\mathrm{~m})$ & 21,15 & 29,90 \\
$\mathrm{~L}_{1}($ Şerit Gen $(\mathrm{m}))$ & 5,35 & 4,90 \\
$\mathrm{~L}_{2}($ Şerit Gen $(\mathrm{m}))$ & 5,00 & 4,70 \\
$\Delta \mathrm{v}(\mathrm{m})$ & 5,75 & 5,15 \\
$\Delta \mathrm{u}(\mathrm{m})$ & 5,05 & 4,75 \\
\hline
\end{tabular}

Turbo kavşakların kavşak alanı ve ilk maliyetleri fazla olmasına karşın sinyalize kavşaklara göre kapasitesi yaklaşık \%30 fazla olması nedeniyle kuyruk uzunluğu ve gecikmeler azaldığından yaşam döngü maliyetleri daha düşüktür [18].

Çok şeritli dönel kavşaklarla turbo dönel kavşaklar güvenlik açısından karşılaştırıldığında Şekil 5 'te görüleceği üzere çok şeritli dönel kavşaklarda sürücünün doğru ve düzensiz davranış biçimine göre olası çakışma sayıları sırasıyla 24, 32 noktada, turbo kavşaklarda ise kavşak kolu sayısı ve tipine göre çakışma sayıları 9 ile 24 nokta arasında değişmektedir. Trafik işaretleriyle düzenlenmiş pasif kontrollü kavşaklara göre güvenliği yüksek olan basit turbo kavşaklarda ise ayırıcılar nedeniyle çakışma 14 noktada (Şekil 6) meydana gelmektedir.

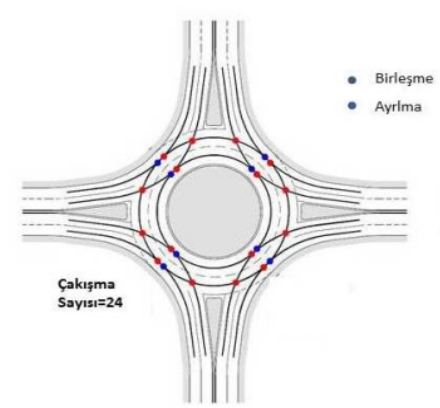

a) Doğru

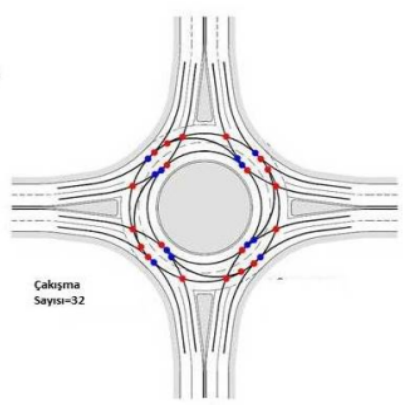

b) Düzensiz

Şekil 5. Sürücü davranışına göre dönel kavşaklarda olası çakışma sayısı[11] 


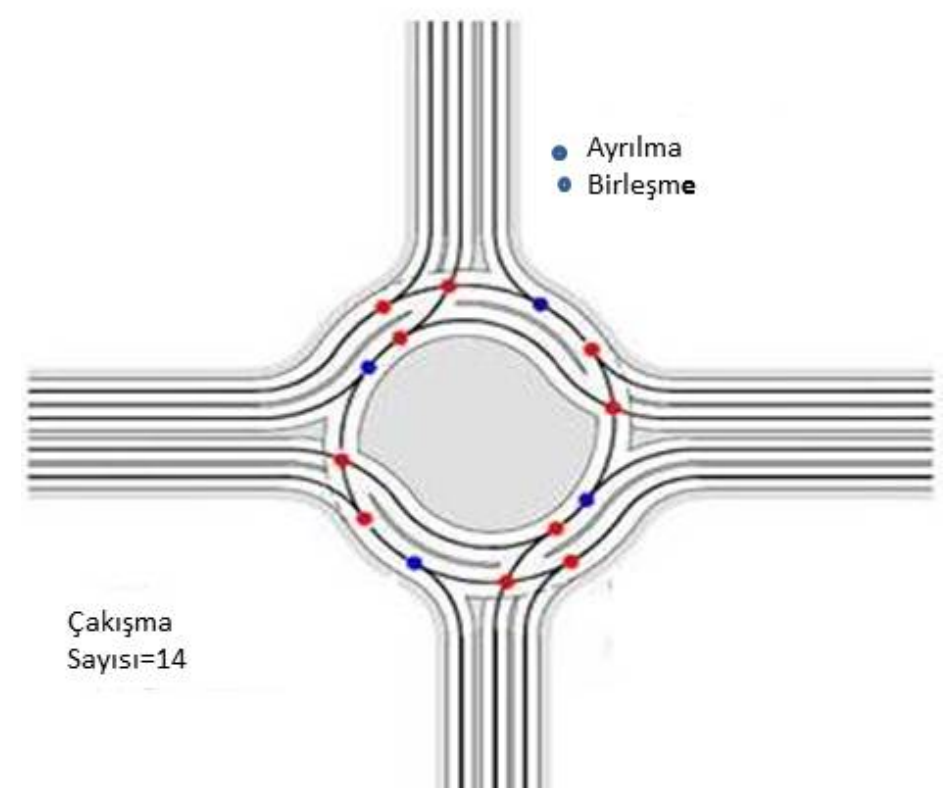

Şekil 6. Basit turbo kavşakların olası çakışma sayısı[11]

Dönel kavşak kollarının kapasite hesaplamalarında kullanılan formül parametreleri kavşak tasarımının ana prensiplerinden güvenlik ve hizmet düzeyi seviyesini etkileyen en önemli faktörlerden olan insan ve trafik faktörleriyle ilişkilidir. Kapasite hesaplamaları genel olarak alan gözlemlerine dayanan regresyon analizi, boşluk kabulü teorisi olmak üzere iki metodoloji ile analitik ve simülasyon modellerle yapılmaktadır[19].Boşluk kabulüne dayanan metodoloji modelleri kavşakta dağılan trafik akışının üssel bir fonksiyonu olarak kapasiteyi ifade eden analitik modellerdir. Çok sayıda modelin olduğu boşluk kabulü metodolojisine tek şeritli giriş için Siegloch, Cowan-M3 modeli, iki şeritli girişler için ise iki şeritli dönel kavşaklar için tali yol kapasitesini Cowan-M3 dağılımı kullanarak hesaplayan Troutbeck modelini genişleten Cowan-M3 2Lve Brilon modeli örnek verilebilir [20].

Turbo kavşakların ilk tasarımını yapan Fortuijn, Troutbeck'in modelini genişleterek ve Hollanda'da kavşak alanlarından elde edilen veriler sonucunda Tanner Demet Modelinin ø parametresini dikkate alarak; ana yönde trafiğin olduğu kollarda sağa sola, tali yollarda ise sağa dönüş kapasitesi Eşitlik 1 ile, tali kollarda sola dönüş kolları için ise Eşitlik 2 ile hesaplamıştır [21].

$$
\begin{aligned}
& \mathrm{C}=\mathrm{q}_{\mathrm{y}}\left(1-\frac{\Delta \cdot \mathrm{q}_{\mathrm{y}}}{3600}\right) \cdot \frac{\mathrm{e}^{\frac{-\mathrm{q}_{\mathrm{y}}\left(\mathrm{T}_{\mathrm{y}}-\Delta\right)}{3600}}}{1-\mathrm{e}^{\frac{-\mathrm{q}_{\mathrm{y}} \mathrm{T}_{\mathrm{f}}}{3600}}} \\
& \mathrm{C}=\left(\mathrm{q}_{\mathrm{u}}+q_{y}\right)\left(1-\frac{\Delta \mathrm{q}_{\mathrm{u}}}{3600}\right)\left(1-\frac{\Delta \mathrm{q}_{\mathrm{y}}}{3600}\right) \frac{\mathrm{e}^{\frac{\left(-\mathrm{q}_{\mathrm{u}}\left(\mathrm{T}_{\mathrm{u}}-\Delta\right) \cdot\left(-\mathrm{q}_{\mathrm{y}}\left(T_{Y}-\Delta\right)\right.\right.}{3600}}}{1-\mathrm{e}^{\frac{\left(-\left(\mathrm{q}_{\mathrm{U}}+\mathrm{q}_{\mathrm{y}}\right) \cdot \mathrm{T}_{\mathrm{f}}\right.}{3600}}}
\end{aligned}
$$

C kavşak kolu kapasitesi,

$\mathrm{q}_{\mathrm{y}}, \mathrm{qu}_{\mathrm{u}}$ : Kavşak içerisinde giriş kolu önüne yakın ve uzak şeritlerde trafik akımı

$\mathrm{T}_{\mathrm{y}}$. Kavşak içerisinde giriş kolu önüne yakın şeritlerde taşıtlar arası takip aralığı(sn)

$\mathrm{T}_{\mathrm{u}}$ : Kavşak içerisinde giriş kolu önüne uzak şeritlerde taşıtlar arası takip aralığı (sn)

$\mathrm{T}_{\mathrm{f}}$ : Giriş yönümde taşıtlar arası takip aralığı(sn),

$\mathrm{T}_{\mathrm{c}}$ : Şeritlerde kritik taşıt aralığg 1 (sn)

$\Delta$ : Kavşak şeritlerinde taşıtlar arasında minimum takip aralığı (1,8 sn-2 sn) 
Genelleştirici Hagring kapasite eşitliğimde ana yön akımından bağımsız tali yönlerin kapasite hesaplamaları; tali yönden gelecek trafik akımının önündeki şerit sayısına göre sağa dönüş için Eşitlik 3 ile sola dönüş için ise Eşitlik 4 ile yapılmaktadır [22].

$C=\frac{q_{u, y} \emptyset e^{-\lambda\left(T_{c}-\Delta\right)}}{1-e^{-\lambda T_{f}}}$

$C=\frac{\exp \left\{-\left(\lambda_{1}+\lambda_{2}\right)\left(T_{c}-\Delta\right)\right]\left(\lambda_{1}+\lambda_{2}\right) \emptyset_{1} \emptyset_{2}}{\left[1-\exp \left[-T_{f}\left(\lambda_{1}+\lambda_{2}\right)\right]\right]\left(\emptyset_{1}+\Delta \lambda_{1}\right)\left(\emptyset_{2}+\Delta \lambda_{2}\right)}$

$\lambda=\frac{\emptyset q_{c}}{1-\Delta q_{y, u}}$

$q_{y, u}<0,5$ ise $\emptyset=1$

$0,178<q_{y, u} \leq 0,5$ ise $\emptyset=1,553 .\left(1-2 . q_{y, u}\right)$

$q_{y u}>0,5$ ise $\emptyset=0$

$\lambda_{\mathrm{i}}, \varnothing_{\mathrm{i}}$ : Kavşağa giriş kolu önünde Cowan M3 Model parametreleri,

$\mathrm{q}_{1}, \mathrm{q}_{3}, \mathrm{q}_{2}$ : Kavşağa girecek trafiğin sola, sağa ve karşı kola akım talebi,

Ana ve tali girişlerde trafik akımı oranları ve şeritlerde trafik akımı (Şekil 7) hesaplama eşitlikleri aşağıda gösterilmiştir.

$$
\begin{aligned}
& \rho_{a}=\frac{C_{\text {ansă }}\left(q_{1}+q_{2}\right)-C_{\text {anasol }} q_{3}}{q_{2}\left(C_{\text {anasă }}+C_{\text {anasol }}\right)} \quad \rho \in(0,1) \\
& \rho_{t}=\frac{C_{\text {talisă }}\left(q_{1}+q_{2}+q_{3}\right)}{q_{2}\left(C_{\text {talisă }}+C_{\text {talisol }}\right)} \quad \rho \in(0,1) \\
& q_{a s ̧-s o l}=q_{1}+\left(1-\rho_{a}\right) \\
& q_{a s ̧-s a \breve{g}}=q_{2} \rho_{a}+q_{3} \\
& q_{t \text { ş-sol }}=\left(q_{1}+q_{2}\right)+\left(1-\rho_{t}\right) q_{3} \\
& q_{t s ̧-s a \mathrm{~g}}=\rho_{t} \cdot q_{3}
\end{aligned}
$$

$\rho_{\mathrm{a}}, \rho_{\mathrm{t}}$ : Ana ve tali yönlerde trafik akımı oranları,

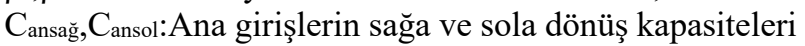

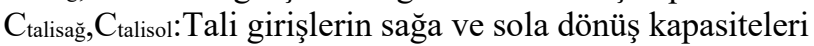

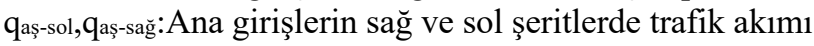

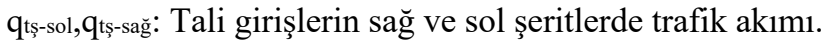




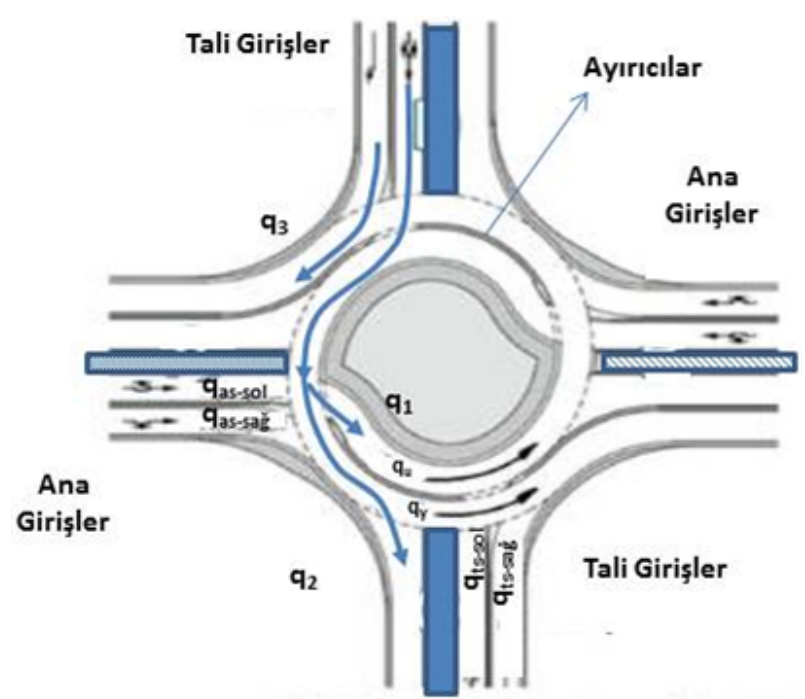

Şekil 7. Basit turbo kavşaklarda ana ve tali kollarda trafik akımı

\section{Metodoloji}

Bingöl il merkezinin güneyiyle, Elâzığ-Muş devlet yoluna bağlantıyı sağlayan mevcut Düzağaç kavşağında, Karayolları Genel Müdürlüğünün sorumluğunda bulunan devlet yolunun 2016 yılı ortalama günlük trafiği Uydukent kolunda ise 2019 yılı zirve saatte (16.30-17.30) trafik sayımları göre kollarda uygulanan sinyalizasyon süreleri dikkate alınarak yol kullanıcı maliyetleri içerisinde bulunan taşıt işletme maliyetlerinden yakıt tüketimi ve durma ve hareketlenme günlük ortalama maliyetleri hesaplanacaktır. Bu maliyetlerin azaltılması için mevcut kavşağın son yıllarda Avrupa ülkelerinde yaygın olarak yapılmaya başlanan turbo dönel kavşak veya alt geçitli turbo dönel kavşak yapılması durumunda kavşak kollarında belirlenen senaryoya göre kapasite ve kavşak kollarında şerit doygunluk yüzdeleri hesaplanarak performansı değerlendirilecektir.

\section{Düzağaç Kavşağının Genel Değerlendirmesi}

Düzağaç kavşağının mevcut durumu ve kollarda uygulanan sinyalizasyon süreleri Şekil 8'de gösterilmiş olup; bu kavşağın sinyalizasyon süreleri gün boyunca aynı olduğu kabul edildiğinde her bir kol 24 saat içerisinde ortalama 5,50 saat (100x30x24/130) trafiğe açık olacağından bu durum kavşă̆ kullanan yol kullanıcı maliyetlerini artırmaktadır. Bu kavşağa ait kolların yıllık ortalama günlük trafik sayısının \% 80'in 08.00-20.00, \%20'sinin 20.00-08.00 saatleri arasında geçtiği kabul edilmiştir. Bu durumunda ortalama 130 sn içerisinde kavşağa girecek her bir kolda ortalama olarak bekleyecek ve geçecek taşıt sayıları hesaplamamış, zirve saatte taşıtların birim otomobil eşdeğerleri Tablo 2'de gösterilmiştir. Kavşağa giren taşıtların kırmızı ışık nedeniyle durması ve sarı ışıkla beraber ivmelenerek hızlanması durumunda NCHRP 133 Metoduna [23] göre hesaplanan maliyetler Tablo 3'de taşıtların beklerken rölantide çalışması durumunda ise yakıt birim fiyatı ortalama 6,50 TL alınarak hesaplanan maliyetler Tablo 4'de gösterilmiştir [26]. Kavşak kullanıcılarının seyahat, gecikme, emisyon, motor yağı ve taşıt amortisman maliyetleri hesaplamalara katılmamasına rağmen bu kavşağın yol kullanıcılarına yıllık maliyeti 3.760.960 TL (8433x365+1871x365) olup; günlük olarak taşıt başına ortalama maliyet ise 0,92 TL'dir 


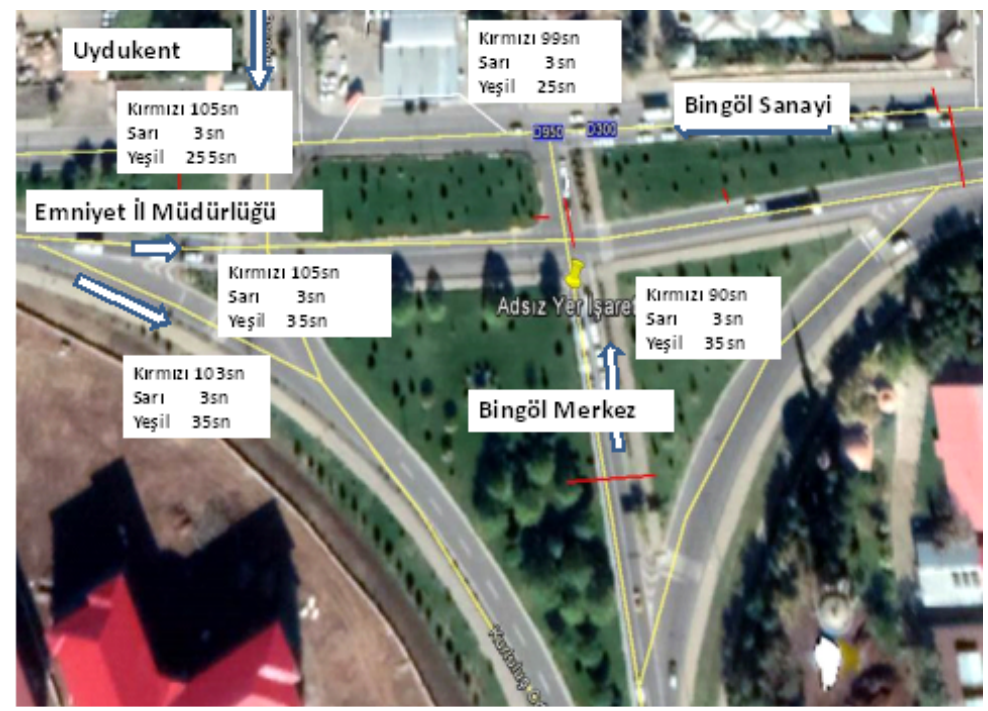

Şekil 8. Düzağaç kavşak kollarının sinyalizasyon süreleri

Tablo 2. Kavşak kollarında 08.00-20,20.00-08.00 saatleri arası bir fazda geçen ve bekleyen taşıt sayıları

\begin{tabular}{|c|c|c|c|c|c|c|c|c|c|c|}
\hline $\begin{array}{l}\text { Kavşak } \\
\text { Kolu }\end{array}$ & Taşıt & $\begin{array}{c}2015 \\
\text { Yllı } \\
\text { YOGT } \\
\text { (A) }\end{array}$ & $\begin{array}{l}\text { Ort. Bir } \\
\text { Yöne } \\
\text { YOGT } \\
(\mathbf{B}=\mathbf{A} / \mathbf{2})\end{array}$ & $\begin{array}{c}\text { Proje } \\
\text { 30. Saat } \\
\text { Trafíği } \\
(C=B / 6)\end{array}$ & $\begin{array}{l}\text { Otomobil } \\
\text { Eşdeger } \\
\text { Faktörü } \\
\text { (D) }\end{array}$ & $\begin{array}{l}\text { Proje } \\
\text { 30. Saat } \\
\text { Birim } \\
\text { Otol } \\
\text { Eşdegeri } \\
\text { (E=DxC) }\end{array}$ & $\begin{array}{c}\text { Saatler (08.00- } \\
20.00) \text { Arası } \\
\text { 100 Saniyede } \\
\text { Ort. Bekleyen } \\
\text { Taşıt Sayısı } \\
(\text { F1=100x0,8xB } \\
/(12 \times 3600))\end{array}$ & $\begin{array}{c}\text { Saatler } \\
(08.00-20.00) \\
\text { Arası 30 } \\
\text { Saniyede Ort. } \\
\text { Geçen Taşıt } \\
\text { Sayısı } \\
(\text { G1=30x0.8xB } \\
/(12 \times 3600))\end{array}$ & $\begin{array}{c}\text { Saatler(20.00- } \\
\text { 08.00) Arası } \\
\text { 100 Saniyede } \\
\text { Ort. Bekleyen } \\
\text { Taşıt Sayısı } \\
(\text { F2=100x0.2xB } \\
/(12 \times 3600))\end{array}$ & $\begin{array}{c}\text { Saatler } \\
(20.00-08.00) \\
\text { Arası 30 } \\
\text { Saniyede Ort. } \\
\text { Geçen Taşıt } \\
\text { Sayısı } \\
(\text { G2=30x0,2xB } \\
/(12 \times 3600)) \\
\end{array}$ \\
\hline \multirow{6}{*}{$\begin{array}{l}\text { Bingöş } \\
\text { Sanayi }\end{array}$} & Otomobil & 4965 & 2483 & 414 & 1 & 414 & 4,60 & 1,38 & 1,15 & 0,34 \\
\hline & $\begin{array}{c}\text { Orta Yüklü } \\
\text { Ticari Tasıt }\end{array}$ & 563 & 282 & 47 & 1,2 & 56 & 0,52 & 0,16 & 0,13 & 0,04 \\
\hline & Otobüs & 114 & 57 & 10 & 1,5 & 14 & 0,11 & 0,03 & 0,03 & 0,01 \\
\hline & Kamyon & 1238 & 619 & 103 & 2 & 206 & 1,15 & 0,34 & 0,29 & 0,09 \\
\hline & $\begin{array}{l}\text { Kamyon+ } \\
\text { Römork }\end{array}$ & 231 & 116 & 19 & 2,2 & 42 & 0,21 & 0,06 & 0,05 & 0,02 \\
\hline & TOPLAM & 7111 & 3556 & 593 & & 733 & 6,58 & 1,98 & 1,65 & 0,49 \\
\hline \multirow{6}{*}{$\begin{array}{l}\text { Emiyet } \\
\text { İl Müd }\end{array}$} & Otomobil & 3484 & 1742 & 290 & 1 & 290 & 3,23 & 0,97 & 0,81 & 0,24 \\
\hline & $\begin{array}{l}\text { Orta Yüklü } \\
\text { Ticari Taşıt }\end{array}$ & 241 & 121 & 20 & 1,1 & 22 & 0,22 & 0,07 & 0,06 & 0,02 \\
\hline & Otobüs & 106 & 53 & 9 & 1,5 & 13 & 0,10 & 0,03 & 0,02 & 0,01 \\
\hline & Kamyon & 419 & 210 & 35 & 2 & 70 & 0,39 & 0,12 & 0,10 & 0,03 \\
\hline & $\begin{array}{l}\text { Kamyon+ } \\
\text { Römork }\end{array}$ & 266 & 133 & 22 & 2,2 & 49 & 0,25 & 0,07 & 0,06 & 0,02 \\
\hline & TOPLAM & 4516 & 2258 & 376 & & 444 & 4,18 & 1,25 & 1,05 & 0,31 \\
\hline \multirow{6}{*}{$\begin{array}{l}\text { Bimgöl } \\
\text { Merkezi }\end{array}$} & Otomobil & 4319 & 2160 & 360 & 1 & 360 & 4,00 & 1,20 & 1,00 & 0,30 \\
\hline & $\begin{array}{l}\text { Orta Yüklü } \\
\text { Ticari Taşıt }\end{array}$ & 478 & 239 & 40 & 1,1 & 44 & 0,44 & 0,13 & 0,11 & 0,03 \\
\hline & Otobüs & 18 & 9 & 2 & 1,5 & 2 & 0,02 & 0,01 & 0,00 & 0,00 \\
\hline & Kamyon & 993 & 497 & 83 & 2 & 166 & 0,92 & 0,28 & 0,23 & 0,07 \\
\hline & $\begin{array}{l}\text { Kamyon+ } \\
\text { Römork }\end{array}$ & 106 & 53 & 9 & 2,2 & 19 & 0,10 & 0,03 & 0,02 & 0,01 \\
\hline & TOPLAM & 5914 & 2957 & 493 & & 591 & 5,48 & 1,64 & 1,37 & 0,41 \\
\hline \multirow{6}{*}{$\underset{*}{\text { Uydukent }}$} & Otomobil & 1629 & 1629 & 272 & 1 & 272 & 3,02 & 0,91 & 0,75 & 0,23 \\
\hline & $\begin{array}{l}\text { Orta Yüklü } \\
\text { Ticari Taşıt }\end{array}$ & 657 & 657 & 110 & 1,1 & 120 & 1,22 & 0,37 & 0,30 & 0,09 \\
\hline & Otobüs & 81 & 81 & 14 & 1,5 & 20 & 0,15 & 0,05 & 0,04 & 0,01 \\
\hline & Kamyon & 18 & 18 & 3 & 2 & 6 & 0,03 & 0,01 & 0,01 & 0,00 \\
\hline & $\begin{array}{l}\text { Kamyon+ } \\
\text { Römork }\end{array}$ & 9 & 9 & 2 & 2,2 & 3 & 0,02 & 0,01 & 0,00 & 0,00 \\
\hline & TOPLAM & 2394 & 2394 & 399 & & 422 & 4,43 & 1,33 & 1,11 & 0,33 \\
\hline
\end{tabular}


İhsan GÜZEL

Tablo 3. Taşıtların durma ve ivmelenme maliyetleri

\begin{tabular}{|c|c|c|c|c|c|c|c|}
\hline \multirow[b]{2}{*}{$\begin{array}{c}\text { Kavşak } \\
\text { Kolu }\end{array}$} & \multicolumn{4}{|c|}{ Ort Bekleyen Taşıt Sayısı (100 Saniye) } & \multirow{2}{*}{$\begin{array}{c}\text { Günde Ortalama } \\
\text { Bekleyen Taşıt Sayısı } \\
\text { (H=Tx86400/130) }\end{array}$} & \multirow[b]{2}{*}{$\begin{array}{c}\text { B Fiyat } \$ / 1000 \\
\text { Durma } \\
\text { ( I) }\end{array}$} & \multirow[b]{2}{*}{$\begin{array}{c}\text { Maliyet } \\
(\$) \\
(\mathbf{J}=\mathbf{H} \mathbf{x} \\
\mathbf{I} / \mathbf{1 0 0 0})\end{array}$} \\
\hline & Taşııt & $\begin{array}{c}\text { Saat } \\
(08.00- \\
20.00) \\
\text { Aralığında } \\
\text { (F1) }\end{array}$ & $\begin{array}{c}\text { Saat } \\
(20.00- \\
08.00) \\
\text { Aralığında } \\
\text { (F2) }\end{array}$ & $\begin{array}{l}\text { Toplam } \\
\text { (T) }\end{array}$ & & & \\
\hline $\begin{array}{l}\text { Bingöl } \\
\text { Sanayi }\end{array}$ & $\begin{array}{l}\text { Otomobil } \\
\text { Orta Yüklü Ticari Taşıt } \\
\text { Otobüs } \\
\text { Kamyon } \\
\text { Kamyon+ Römork }\end{array}$ & $\begin{array}{l}4,60 \\
0,52 \\
0,11 \\
1,15 \\
0,21 \\
\end{array}$ & $\begin{array}{l}1,15 \\
0,13 \\
0,03 \\
0,29 \\
0,05\end{array}$ & $\begin{array}{l}5,75 \\
0,65 \\
0,13 \\
1,43 \\
0,27 \\
\end{array}$ & $\begin{array}{c}3819,23 \\
433,08 \\
87,69 \\
952,31 \\
177,69 \\
\end{array}$ & \begin{tabular}{|l|}
38,83 \\
38,83 \\
86,64 \\
347,44 \\
347,44 \\
\end{tabular} & $\begin{array}{c}148,301 \\
16,816 \\
7,598 \\
330,870 \\
61,737 \\
\end{array}$ \\
\hline $\begin{array}{c}\text { Emniyet } \\
\text { İl } \\
\text { Müd. }\end{array}$ & $\begin{array}{l}\text { Otomobil } \\
\text { Orta Yüklü Ticari Taşıt } \\
\text { Otobüs } \\
\text { Kamyon } \\
\text { Kamyon+ Römork } \\
\end{array}$ & $\begin{array}{l}3,23 \\
0,22 \\
0,10 \\
0,39 \\
0,25 \\
\end{array}$ & $\begin{array}{l}0,81 \\
0,06 \\
0,02 \\
0,10 \\
0,06\end{array}$ & $\begin{array}{l}4,03 \\
0,28 \\
0,12 \\
0,48 \\
0,31 \\
\end{array}$ & $\begin{array}{c}2680,00 \\
185,38 \\
81,54 \\
322,31 \\
204,62 \\
\end{array}$ & \begin{tabular}{|l|}
38,83 \\
38,83 \\
86,64 \\
347,44 \\
347,44 \\
\end{tabular} & $\begin{array}{c}104,064 \\
7,198 \\
7,064 \\
111,983 \\
71,092\end{array}$ \\
\hline $\begin{array}{l}\text { Bingölr } \\
\text { Merkezi }\end{array}$ & $\begin{array}{l}\text { Otomobil } \\
\text { Orta Yüklü Ticari Taşıt } \\
\text { Otobüs } \\
\text { Kamyon } \\
\text { Kamyon+ Römork }\end{array}$ & $\begin{array}{l}4,00 \\
0,44 \\
0,02 \\
0,92 \\
0,10 \\
\end{array}$ & $\begin{array}{l}1,00 \\
0,11 \\
0,00 \\
0,23 \\
0,02 \\
\end{array}$ & $\begin{array}{l}5,00 \\
0,55 \\
0,02 \\
1,15 \\
0,12 \\
\end{array}$ & $\begin{array}{c}3322,31 \\
367,69 \\
13,85 \\
763,85 \\
81,54 \\
\end{array}$ & $\begin{array}{c}38,83 \\
38,83 \\
86,64 \\
347,44 \\
347,44 \\
\end{array}$ & $\begin{array}{c}129,005 \\
14,277 \\
1,200 \\
265,391 \\
28,330 \\
\end{array}$ \\
\hline Uydukent & $\begin{array}{l}\text { Otomobil } \\
\text { Orta Yüklü Ticari Taşıt } \\
\text { Otobüs } \\
\text { Kamyon } \\
\text { Kamyon+ Römork }\end{array}$ & $\begin{array}{l}3,02 \\
1,22 \\
0,15 \\
0,03 \\
0,02\end{array}$ & $\begin{array}{l}0,75 \\
0,30 \\
0,04 \\
0,01 \\
0,00\end{array}$ & $\begin{array}{l}3,77 \\
1,52 \\
0,19 \\
0,04 \\
0,02\end{array}$ & $\begin{array}{l}2506,15 \\
1010,77 \\
124,62 \\
27,69 \\
13,85\end{array}$ & \begin{tabular}{|l|}
38,83 \\
38,83 \\
86,64 \\
347,44 \\
347,44 \\
\end{tabular} & $\begin{array}{l}97,314 \\
39,248 \\
10,797 \\
9,621 \\
4,811\end{array}$ \\
\hline \multirow{2}{*}{\multicolumn{6}{|c|}{ F1,F2 Tablo -2'de açıklanmıştır. }} & TOPLAM (\$) & 1466,717 \\
\hline & & & & & & $\begin{array}{l}2019 \text { Yllt } \\
\text { TOPLAM (TL) }\end{array}$ & 8433,624 \\
\hline
\end{tabular}

Tablo 4. Taşıtların rolantide çalışma maliyetleri

\begin{tabular}{|c|c|c|c|c|c|c|c|c|}
\hline \multirow[b]{2}{*}{$\begin{array}{c}\text { Kavşak } \\
\text { Kolu }\end{array}$} & \multicolumn{4}{|c|}{ Ortalama Bekleyen Taşıt Sayısı (100 Saniye) } & \multirow{2}{*}{$\begin{array}{l}100 \\
\text { Saniyede } \\
\text { Rolantide } \\
\text { Yakıt } \\
\text { Tüketimi } \\
\text { Lt }(L)\end{array}$} & \multirow{2}{*}{$\begin{array}{l}2019 \text { Yılı } \\
\text { Yakıt Birim } \\
\text { FiyatI TL } \\
\text { (M) }\end{array}$} & \multirow{2}{*}{$\begin{array}{c}100 \\
\text { Saniyede } \\
\text { Maliyet TL } \\
(\text { MM } \\
=\text { MxLxTB) }\end{array}$} & \multirow{2}{*}{$\begin{array}{c}\text { Günlük Maliyet } \\
\text { TL } \\
\text { (GM }= \\
\text { 86400xMM/130 }\end{array}$} \\
\hline & Taşıt & $\begin{array}{l}\text { Saat }(08.00 \\
-20.00) \\
\text { Aralığında } \\
\quad \text { (F1) }\end{array}$ & $\begin{array}{l}\text { Saat(20.00- } \\
\text { 08.00) } \\
\text { Aralığında } \\
\quad(\mathbf{F} 2)\end{array}$ & $\begin{array}{c}\begin{array}{c}\text { Ort Toplam } \\
(\mathrm{TB}=(\mathrm{F} 1+\mathrm{F} 2) / 2 \\
)\end{array} \\
\text { ( }\end{array}$ & & & & \\
\hline $\begin{array}{l}\text { Bingöl } \\
\text { Sanayi }\end{array}$ & $\begin{array}{l}\text { Otomobil } \\
\text { Orta Yüklü Ticari Taşıt } \\
\text { Otobüs } \\
\text { Kamyon } \\
\text { Kamyon+ Römork }\end{array}$ & $\begin{array}{l}4,60 \\
0,52 \\
0,11 \\
1,15 \\
0,21\end{array}$ & $\begin{array}{l}1,15 \\
0,13 \\
0,03 \\
0,29 \\
0,05\end{array}$ & $\begin{array}{l}2,87 \\
0,33 \\
0,07 \\
0,72 \\
0,13\end{array}$ & $\begin{array}{l}0,028 \\
0,042 \\
0,049 \\
0,049 \\
0,049\end{array}$ & $\begin{array}{l}6,5 \\
6,5 \\
6,5 \\
6,5 \\
6,5\end{array}$ & $\begin{array}{l}0,532 \\
0,089 \\
0,021 \\
0,230 \\
0,043\end{array}$ & $\begin{array}{c}353,66 \\
58,90 \\
14,08 \\
152,94 \\
28,54\end{array}$ \\
\hline $\begin{array}{c}\text { Emniyet İl. } \\
\text { Mğd. }\end{array}$ & $\begin{array}{l}\text { Otomobil } \\
\text { Orta Yüklü Ticari Taşıt } \\
\text { Otobüs } \\
\text { Kamyon } \\
\text { Kamyon+ Römork }\end{array}$ & $\begin{array}{l}3,23 \\
0,22 \\
0,10 \\
0,39 \\
0,25\end{array}$ & $\begin{array}{l}0,81 \\
0,06 \\
0,02 \\
0,10 \\
0,06\end{array}$ & $\begin{array}{l}2,02 \\
0,14 \\
0,06 \\
0,24 \\
0,15\end{array}$ & $\begin{array}{l}0,028 \\
0,042 \\
0,049 \\
0,049 \\
0,049\end{array}$ & $\begin{array}{l}6,5 \\
6,5 \\
6,5 \\
6,5 \\
6,5\end{array}$ & $\begin{array}{l}0,373 \\
0,038 \\
0,020 \\
0,078 \\
0,049\end{array}$ & $\begin{array}{c}248,17 \\
25,21 \\
13,10 \\
51,76 \\
32,86 \\
\end{array}$ \\
\hline $\begin{array}{c}\text { Bingöl } \\
\text { ŞMerkez }\end{array}$ & $\begin{array}{l}\text { Otomobil } \\
\text { Orta Yüklü Ticari Taşıt } \\
\text { Otobüs } \\
\text { Kamyon } \\
\text { Kamyon+ Römork }\end{array}$ & $\begin{array}{l}4,00 \\
0,44 \\
0,02 \\
0,92 \\
0,10\end{array}$ & $\begin{array}{l}1,00 \\
0,11 \\
0,00 \\
0,23 \\
0,02\end{array}$ & $\begin{array}{l}2,50 \\
0,28 \\
0,01 \\
0,57 \\
0,06\end{array}$ & $\begin{array}{l}0,028 \\
0,042 \\
0,049 \\
0,049 \\
0,049\end{array}$ & $\begin{array}{l}6,5 \\
6,5 \\
6,5 \\
6,5 \\
6,5\end{array}$ & $\begin{array}{l}0,463 \\
0,075 \\
0,003 \\
0,185 \\
0,020\end{array}$ & $\begin{array}{c}307,65 \\
50,01 \\
2,22 \\
122,67 \\
13,10\end{array}$ \\
\hline Uydukent & $\begin{array}{l}\text { Otomobil } \\
\text { Orta Yüklü Ticari Taşıt } \\
\text { Otobüs } \\
\text { Kamyon } \\
\text { Kamyon+ Römork }\end{array}$ & $\begin{array}{l}3,02 \\
1,22 \\
0,15 \\
0,03 \\
0,02\end{array}$ & $\begin{array}{l}0,75 \\
0,30 \\
0,04 \\
0,01 \\
0,00\end{array}$ & $\begin{array}{l}1,89 \\
0,76 \\
0,09 \\
0,02 \\
0,01\end{array}$ & $\begin{array}{l}0,028 \\
0,042 \\
0,049 \\
0,049 \\
0,049\end{array}$ & $\begin{array}{l}6,5 \\
6,5 \\
6,5 \\
6,5 \\
6,5\end{array}$ & $\begin{array}{l}0,349 \\
0,207 \\
0,030 \\
0,007 \\
0,003\end{array}$ & $\begin{array}{c}232,07 \\
137,46 \\
20,01 \\
4,45 \\
2,22\end{array}$ \\
\hline & & & & & & TOPLAM & 2,815 & 1871,09 \\
\hline
\end{tabular}


Kavşağı kullanan yol kullanıcılarının taşıt işletme maliyetlerinin (yakıt tüketimi, durma kalkma) azaltılması için mevcut Düzağaç kavşak alanında gerekli alt yapı düzenlemelerinde sonra, kavşağın sinyalizasyonuz olarak turbo kavşakların en yüksek kapasiteli tiplerinden biri olan rotor tipi yapılması durumunda olası çakışmalar Şekil 9'da gösterilmiştir.

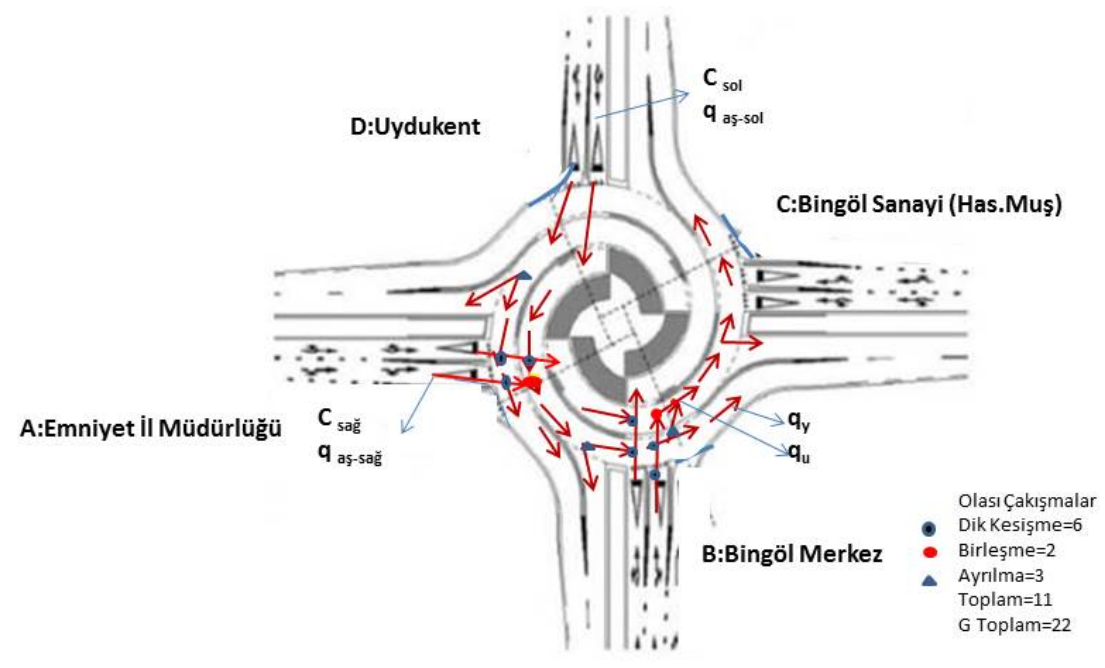

Şekil 9. Rotar tipi turbo kavşak

\section{Uygulanan Trafik Akımı Senaryoları}

Kavşağın zirve saatte birim otomobil eşdeğerlerine göre kapasite hesaplamaları;2016 yılından sonra Karayolları Genel Müdürlüğünün sorumluğundan çıkan Diyarbakır-Genç -Bingöl yolu (Bingöl Şehir Merkezi içinden kavşağa giriş kolu) 2019 yılı YOGT’si 2015 yılı YOGT’sine [24] göre \%25, Elazığ-Muş Devlet yolunun (Emniyet Müdürlüğü, Bingöl Sanayi) 2019 yılı verileri yayınlamadığından diğer yıllara ait artışlar dikkate alınarak 2019 yılı YOGT'sini 2015 yılı YOGT'sine göre \%20 arttığı kabul edilerek yapılmıştır. Tablo 2'de gösterilen zirve saatlerde birim otomobil eşdeğerleri 2019 yılına uyarlanarak Tablo 5'te verilen dağılım senaryosuna göre zirve saatte kollardan kavşağa gelen taşıt trafiğinin kavşak kollarına dağılım sayıları hesaplanmıştır.

Tablo 5. Kavşağa giren taşıt trafiğinin yönlere dağılımı

\begin{tabular}{|c|c|c|c|c|c|c|}
\hline \multicolumn{2}{|c|}{ Kavşağa Giriş Kolu } & \multicolumn{5}{|c|}{$\begin{array}{c}\text { Kollardan Kavşağa Giren Trafiğin Zirve Saatlerde Dağlım } \\
\text { Yönleri }\end{array}$} \\
\hline & & $\mathbf{A}$ & B & $\mathbf{C}$ & D & TOPLAM \\
\hline \multirow{2}{*}{$\begin{array}{l}\text { A:Emniyet İl Müdürlüğüu } \\
\qquad 444 \times 1,20=533\end{array}$} & Dağılım Senaryosu \% & 5 & 40 & 45 & 10 & 100 \\
\hline & Taşıt Sayısı & 27 & 213 & 240 & 53 & 533 \\
\hline \multirow{2}{*}{$\begin{array}{l}\text { B:Bingöl Merkez } \\
591 \times 1,25=739\end{array}$} & Dağılım Senaryosu \% & 55 & 15 & 20 & 10 & 100 \\
\hline & Taşıt Sayısı & 406 & 111 & 148 & 74 & 739 \\
\hline \multirow{2}{*}{$\begin{array}{c}\text { C:Bingöl Sanayi } \\
733 \times 1,20=880\end{array}$} & Dağılım Senaryosu \% & 50 & 40 & 5 & 5 & 100 \\
\hline & Taşıt Sayısı & 449 & 352 & 44 & 44 & 880 \\
\hline \multirow{2}{*}{ D:Uydukent 2019 Yılı 422} & Dağılım Senaryosu \% & 10 & 65 & 20 & 5 & 100 \\
\hline & Taşıt Sayısı & 42 & 274 & 84 & 21 & 422 \\
\hline
\end{tabular}


Kavşağa giriş kollarının önünde bulunan şeritlerde zirve saatlerde trafik akımı değerleri Tablo 5'te gösterilen senaryoya göre hesaplanarak Tablo 6'da gösterilmiştir. Bu değerlere göre en fazla trafik akımı Uydukent ve Emniyet Müdürlüğü kolları önünde meydana gelmiştir. Sola dönüşler için $T_{\mathrm{f}}=3,9 \mathrm{sn} \mathrm{T}_{\mathrm{c}}=2,1 \mathrm{sn} \Delta=2 \mathrm{sn}$ sağa dönüşler için $\mathrm{T}_{\mathrm{f}}=3,6 \mathrm{sn} \mathrm{T}_{\mathrm{c}}=2,1 \mathrm{sn} \Delta=2 \mathrm{sn}$ alınarak [25]; kavşağa giriş kollarında şeritlerin doygunluk yüzdeleri Tablo 7'de belirtilen eşitliklerle hesaplanması sonucunda sol şeritlerde doygunluk, ortalana \%50 seviyesine ulaştığı tespit edilmiştir.

Tablo 6. Kavşak kolu önünde șeritlerde trafik akım

\begin{tabular}{|c|c|c|c|}
\hline \multirow{2}{*}{$\begin{array}{l}\text { Kavşağa Giriş } \\
\text { Kolu }\end{array}$} & \multicolumn{3}{|c|}{ Kavşak Giriş Kolu Önünde Şeritlerde Trafik Akımı } \\
\hline & $\begin{array}{c}\text { Dönel Adaya Göre Şerit } \\
\text { Yeri }\end{array}$ & $\begin{array}{l}\text { Gelen } \\
\text { Trafik } \\
\text { Akım }\end{array}$ & $\begin{array}{c}\text { Gelen Trafik } \\
\text { Akım Sayısı } \\
\text { (B.oto/sa) }\end{array}$ \\
\hline \multirow{8}{*}{$\begin{array}{l}\text { A:Emniyet İl } \\
\text { Müdürlüğü }\end{array}$} & \multirow{4}{*}{ Dış (Girişe yakın :qy) } & BB & 111 \\
\hline & & CB & 352 \\
\hline & & DB & 274 \\
\hline & & TOPLAM & 737 \\
\hline & \multirow{4}{*}{ İç (Girişe uzak, qu) } & $\mathrm{CC}$ & 44 \\
\hline & & DC & 84 \\
\hline & & DD & 21 \\
\hline & & TOPLAM & 150 \\
\hline \multirow{8}{*}{$\begin{array}{c}\text { B:Bingöl Şehir } \\
\text { Merkezi }\end{array}$} & \multirow{4}{*}{ Dış (Girişe yakın , qy $)$} & $\mathrm{AC}$ & 240 \\
\hline & & $\mathbf{C C}$ & 44 \\
\hline & & DC & 84 \\
\hline & & TOPLAM & 368 \\
\hline & \multirow{4}{*}{ İç (Girişe uzak qu) } & AD & 53 \\
\hline & & $\mathbf{A A}$ & 27 \\
\hline & & DD & 21 \\
\hline & & TOPLAM & 101 \\
\hline \multirow{8}{*}{$\begin{array}{l}\text { C:Bingöl } \\
\text { Sanayi }\end{array}$} & \multirow{4}{*}{ Dış (Girişe yakın , qy) } & BD & 74 \\
\hline & & AD & 21 \\
\hline & & DD & 53 \\
\hline & & TOPLAM & 148 \\
\hline & \multirow{4}{*}{ İç (Girişe uzak, qu) } & BA & 406 \\
\hline & & BB & 111 \\
\hline & & DD & 27 \\
\hline & & TOPLAM & 544 \\
\hline \multirow{8}{*}{ D:Uydukent } & \multirow{4}{*}{ Dış (Girişe yakın , qyy) } & CA & 440 \\
\hline & & BA & 406 \\
\hline & & AA & 27 \\
\hline & & TOPLAM & 873 \\
\hline & \multirow{4}{*}{ İç (Girişe uzak,qu) } & CB & 352 \\
\hline & & BB & 111 \\
\hline & & $\mathrm{CC}$ & 44 \\
\hline & & TOPLAM & 507 \\
\hline
\end{tabular}

Tablo 7. Kavşak kollarının kapasiteleri ve şerit doygunluk yüzdeleri

\begin{tabular}{|c|c|c|c|c|c|c|c|c|c|c|c|}
\hline \multirow[t]{2}{*}{$\begin{array}{l}\text { Kavşağa Giriş } \\
\text { Kolu }\end{array}$} & \multicolumn{2}{|c|}{$\begin{array}{c}\text { Kavşak Kolunun } \\
\text { Sağa Sola Dönüş̧ } \\
\text { Kapasiteleri } \\
\text { (B.Oto/sa) }\end{array}$} & \multicolumn{3}{|c|}{$\begin{array}{c}\text { Kavşağa Giriş } \\
\text { Kolunda Sola } \\
\text {,Karşı Kola ve } \\
\text { Sağa Dönen } \\
\text { Taşıt Sayıları } \\
\text { (B.Oto/sa) }\end{array}$} & \multirow{2}{*}{$\begin{array}{c}\text { Kollarda } \\
\text { Sağ Şeridi } \\
\text { Kullanma } \\
\text { Oranı } \rho \\
\text { Eşitlik }[7,8]\end{array}$} & \multirow{2}{*}{$\begin{array}{c}\text { Düzel } \\
\text { tilmiş } \\
\rho^{*}\end{array}$} & \multicolumn{2}{|c|}{$\begin{array}{l}\text { İki Şeritli Giriş } \\
\text { Kolunda Sağa } \\
\text { Sola Dönüş } \\
\text { Trafik Alımı } \\
\text { (B.Oto/sa) }\end{array}$} & \multicolumn{2}{|c|}{$\begin{array}{c}\text { İki Şeritli Giriş Kolunda Şerit } \\
\text { Doygunluğu (\%) }\end{array}$} \\
\hline & $\begin{array}{c}C_{\text {sol }} \\
\text { Eşitlik } \\
{[4,5,6]} \\
\end{array}$ & $\begin{array}{c}C_{\text {sağ }} \\
\text { Eşitlik } \\
{[4,5,6]}\end{array}$ & $q_{1}$ & $\mathbf{q}_{2}$ & $\mathbf{q}_{3}$ & & & $\begin{array}{l}\text { qaş-sağ } \\
\text { Eşit. } \\
\text { [10] }\end{array}$ & $\begin{array}{c}\text { qass-sol } \\
\text { Eşitl. } \\
\text { [9] }\end{array}$ & $D_{\text {sağ }}=q_{\text {aşsag }} / C s_{\text {ağ }}$ & $\mathbf{D}_{\text {sol }}=\mathbf{q}_{\text {ass-sol }} / \mathbf{C}_{\text {sol }}$ \\
\hline $\begin{array}{l}\text { A:Emniyet İl } \\
\text { Müdürlüğü }\end{array}$ & 647 & 727 & 80 & 240 & 213 & 0,287 & 0,287 & 282 & 251 & 38,79 & 38,79 \\
\hline $\begin{array}{c}\text { B:Bingöl } \\
\text { Merkez }\end{array}$ & 1120 & 1174 & 517 & 74 & 148 & 3,119 & 1,000 & 222 & 517 & 18,88 & 46,20 \\
\hline $\begin{array}{c}\text { C:Bingöl } \\
\text { Sanayi } \\
\end{array}$ & 868 & 939 & 396 & 440 & 44 & 0,939 & 0,939 & 457 & 423 & 48,70 & 48,70 \\
\hline D:Uydukent & 334 & 408 & 106 & 274 & 42 & 0,691 & 0,691 & 232 & 190 & 56,80 & 56,80 \\
\hline
\end{tabular}


Alt geçitsiz turbo kavşakta doygunluk seviyelerinin azaltılması için kavşağa giren kollarda sağa dönüşlerin kavşağa girmeden sağlanarak alt geçitli turbo kavşak seçeneği uygulanabilir olduğu Google Earth'de yapılan incelemelerden görülmüştür (Şekil 10). Bu durumda A-C ve C-A yönlerinde trafiğin Tablo 8'de gösterilen yüzdelerle alt geçit kullanım senaryosuna göre zirve saatte rotor tipi turbo kavşağı kullanacak taşıt sayıları hesaplanmıştır. Alt geçitli turbo kavşak tasarımında ekonomiklik göz önüne alınarak; mevcut kavşağın A-C, C-A ve B kollarının yatay güzergâhının değiştirilmemesi, kavşağın alanının genel görünümünün bozulmaması ve asgari kamulaştırma yapılamasına dikkat edilmelidir.

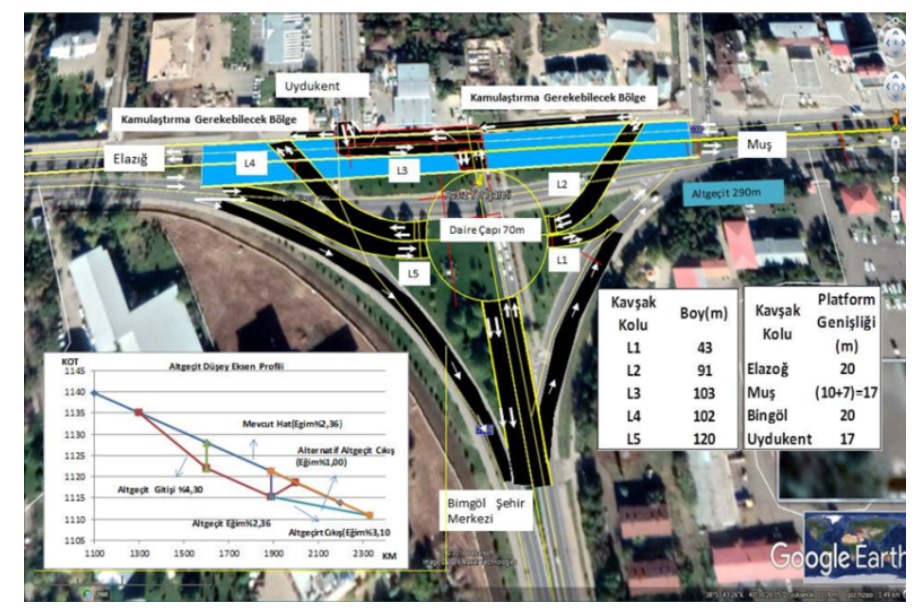

Şekil 10. Düzağaç kavşağının alt geçitli turbo dönel kavşak düzenlenmesi

Tablo 8. Zirve saatlerde turbo kavşak kollarında taşıt sayıları

\begin{tabular}{|c|c|c|c|c|c|c|c|c|c|}
\hline $\begin{array}{c}\text { Kavşak } \\
\text { Kolu }\end{array}$ & Taşıt & $\begin{array}{c}\text { Proje 30. } \\
\text { Saat Birim } \\
\text { Otomobil } \\
\text { Eşdegeri } \\
\text { (E=DxC) }\end{array}$ & $\begin{array}{c}2019 \\
\text { YIılına } \\
\text { Dönüşüm } \\
\text { Katsayısı } \\
\text { (DY) }\end{array}$ & $\begin{array}{c}\text { Proje } 30 . \\
\text { Saat } \\
\text { Trafíği } \\
\text { Birim } \\
\text { Otomobil } \\
\text { Eşdegeri } \\
\text { (2019 Yılı } \\
\text { YT=ExDY) }\end{array}$ & $\begin{array}{c}\text { Alt } \\
\text { Geçitten } \\
\text { Gecen \% } \\
\text { (AG) }\end{array}$ & $\begin{array}{c}\text { Alt } \\
\text { Gecitten } \\
\text { Geçen } \\
\text { Taşıt Sayıs } \\
\text { (BS=AGxY } \\
\text { T/100) }\end{array}$ & $\begin{array}{c}\text { Sağa } \\
\text { Dönü̈ş } \\
\text { \% (SD) }\end{array}$ & $\begin{array}{c}\text { Sağa } \\
\text { Dönen } \\
\text { B.Oto } \\
\text { Sayısı } \\
\text { (SDB=(YT- } \\
\text { BS)xSD/10 } \\
\text { 0) }\end{array}$ & $\begin{array}{c}2019 \\
\text { Yılında Alt } \\
\text { Geçit } \\
\text { Üzerinde } \\
\text { Turbo } \\
\text { Kavşağı } \\
\text { Kullanan } \\
\text { (TK=YT- } \\
\text { BS-SDB) } \\
\end{array}$ \\
\hline \multirow{6}{*}{$\begin{array}{c}\text { Bingöl } \\
\text { Samayi } \\
\text { (Hastane, } \\
\text { Muş) }\end{array}$} & Otomıbil & 414 & 1,2 & 497 & 50 & 248 & 5 & 25 & 223 \\
\hline & Orta Yüklü Ticari Taşıt & 56 & 1,2 & 68 & 50 & 34 & 5 & 3 & 30 \\
\hline & Otobüs & 14 & 1,2 & 17 & 50 & 9 & 5 & 1 & 8 \\
\hline & Kamyon & 206 & 1,2 & 248 & 50 & 124 & 5 & 12 & 111 \\
\hline & Kamyon+ Römork & 42 & 1,2 & 51 & 50 & 25 & 5 & 3 & 23 \\
\hline & TOPLAM & 733 & 1,2 & 880 & & 440 & & 44 & 396 \\
\hline \multirow{6}{*}{$\begin{array}{l}\text { Emniyet } \\
\text { İl Müd. }\end{array}$} & Otomobil & 290 & 1,2 & 348 & 45 & 157 & 40 & 139 & 52 \\
\hline & Orta Yüklü Ticari Taşıt & 22 & 1,2 & 27 & 45 & 12 & 40 & 11 & 4 \\
\hline & Otobüs & 13 & 1,2 & 16 & 45 & 7 & 40 & 6 & 2 \\
\hline & Kamyon & 70 & 1,2 & 84 & 45 & 38 & 40 & 34 & 13 \\
\hline & Kamyon+ Römork & 49 & 1,2 & 59 & 45 & 26 & 40 & 23 & 9 \\
\hline & TOPLAM & 444 & 1,2 & 533 & & 240 & & 213 & 80 \\
\hline \multirow{6}{*}{$\begin{array}{l}\text { Bingöl- } \\
\text { Şehir } \\
\text { Merkezi }\end{array}$} & Otomobil & 360 & 1,25 & 450 & 0 & 0 & 20 & 90 & 360 \\
\hline & Orta Yüklü Ticari Taşıt & 44 & 1,25 & 55 & 0 & 0 & 20 & 11 & 44 \\
\hline & Otobüs & 2 & 1,25 & 3 & 0 & 0 & 20 & 1 & 2 \\
\hline & Kamyon & 166 & 0 & 0 & 0 & 0 & 20 & 0 & 0 \\
\hline & Kamyon+ Römork & 19 & 0 & 0 & 0 & 0 & 20 & 0 & 0 \\
\hline & TOPLAM & 591 & 1 & 507 & & 0 & & 101 & 406 \\
\hline \multirow{7}{*}{ Uydukent } & Otomobil & 272 & 1 & 272 & 0 & 0 & 10 & 27 & 244 \\
\hline & Orta Yüklü Ticari Taşıtt & 120 & 1 & 120 & 0 & 0 & 10 & 12 & 108 \\
\hline & Otobüs & 20 & 1 & 20 & 0 & 0 & 10 & 2 & 18 \\
\hline & Kamyon & 6 & 1 & 6 & 0 & 0 & 10 & 1 & 5 \\
\hline & Kamyon+ Römork & 3 & 1 & 3 & 0 & 0 & 10 & 0 & 3 \\
\hline & TOPLAM & 422 & 1 & 422 & & 0 & & 42 & 379 \\
\hline & G TOPLAM & 2190 & & 2342 & & 680 & & 401 & 1261 \\
\hline
\end{tabular}

Zirve saatte A-C ve C-A yönünde gidecek trafiğin ortalama \%10'unun (A kolu 240x0,1=24: C kolu 440x0,10=44) bu kolların çıkışında bulunan yerleşim yerleri nedeniyle altgeçidi kullanmayacağ düşünülerek; 
turbo kavşağa giren trafiğgin alt geçitsiz turbo kavşak senaryosuna benzer bir senaryo ile yönlere dağılımı Tablo 9'da gösterilmiştir.

Tablo 9. Alt geçitli turbo kavşak kollarında trafik akımının yönlere dağılımı

\begin{tabular}{|c|c|c|c|c|c|c|}
\hline \multicolumn{2}{|c|}{ Kavşağa Giriş Kolu } & \multicolumn{5}{|c|}{$\begin{array}{c}\text { Kollardan Kavşağa Giren Trafiğin Zirve Saatlerde Dağlım } \\
\text { Yönleri }\end{array}$} \\
\hline & & $\mathbf{A}$ & B & $\mathbf{C}$ & D & TOPLAM \\
\hline \multirow{2}{*}{ A:Emniyet İl Müdürlüğü } & $\begin{array}{c}\text { Dağılım } \\
\text { Senaryosu \% }\end{array}$ & 26 & 0 & 23 & 51 & 100 \\
\hline & Taşıt Sayısı & 27 & 0 & 24 & 53 & 104 \\
\hline \multirow[t]{2}{*}{ B:Bingöl Merkez } & $\begin{array}{c}\text { Dağılım } \\
\text { Senaryosu \% }\end{array}$ & 54 & 27 & 0 & 18 & 100 \\
\hline & Taşıt Sayısı & 221 & 111 & 0 & 74 & 406 \\
\hline \multirow[t]{2}{*}{ C:Bingöl Sanayi } & $\begin{array}{c}\text { Dağılım } \\
\text { Senaryosu \% }\end{array}$ & 10 & 80 & 10 & 0 & 100 \\
\hline & Taşıt Sayısı & 44 & 352 & 44 & 0 & 440 \\
\hline \multirow[t]{2}{*}{ D:Uydukent 2019 Yılı 422} & $\begin{array}{c}\text { Dağılım } \\
\text { Senaryosu \% }\end{array}$ & 0 & 72 & 22 & 6 & 100 \\
\hline & Taşıt Sayısı & 0 & 274 & 84 & 21 & 379 \\
\hline
\end{tabular}

Alt geçitli turbo kavşak kolları önünde trafik akımı alt geçitsiz turbo kavşağa ait hesaplamalarına benzer şekilde yapılarak (Tablo 7) kavşak kollarında sağ ve sol şerit doygunluk yüzdeleri Tablo kapasiteleri ve şerit doygunluk yüzdeleri Tablo10'da gösterilmiş̧ir.

Tablo 10 Altgeçitli turbo, kavşak kollarının kapasiteleri ve şerit doygunluk yüzdeleri

\begin{tabular}{|c|c|c|c|c|c|c|c|c|c|c|c|}
\hline \multirow[t]{2}{*}{$\begin{array}{l}\text { Kavşağa Giriş } \\
\text { Kolu }\end{array}$} & \multicolumn{2}{|c|}{$\begin{array}{c}\text { Kavşak Kolunun } \\
\text { Sağa Sola Dönüş } \\
\text { Kapasiteleri } \\
\text { (B.Oto/sa) }\end{array}$} & \multicolumn{3}{|c|}{$\begin{array}{c}\text { Kavşağa Giriş } \\
\text { Kolunda Sola } \\
\text {,Karşı Kola ve } \\
\text { Sağa Dönen } \\
\text { Taşıt Sayıları } \\
\text { (B.Oto/sa) }\end{array}$} & \multirow{2}{*}{$\begin{array}{c}\text { Kollarda } \\
\text { Sağ Şeridi } \\
\text { Kullanma } \\
\text { Oranı } \rho \\
\text { Eşitlik }[7,8]\end{array}$} & \multirow{2}{*}{$\begin{array}{c}\text { Düzel } \\
\text { tilmiş } \\
\rho^{*}\end{array}$} & \multicolumn{2}{|c|}{$\begin{array}{l}\text { İki Şeritli Giriş } \\
\text { Kolunda Sağa } \\
\text { Sola Dönüş } \\
\text { Trafik Alımı } \\
\text { (B.Oto/sa) }\end{array}$} & \multicolumn{2}{|c|}{$\begin{array}{c}\text { İki Şeritli Giriş Kolunda Şerit } \\
\text { Doygunluğu }(\%)\end{array}$} \\
\hline & $\begin{array}{c}C_{\text {sol }} \\
\text { Eşitlik } \\
{[4,5,6]}\end{array}$ & $\begin{array}{c}C_{\text {sağ }} \\
\text { Eşitlik } \\
{[4,5,6]}\end{array}$ & $\mathbf{q}_{1}$ & $\mathbf{q}_{2}$ & $\mathbf{q}_{3}$ & & & $\begin{array}{l}\text { qaş-sağ } \\
\text { Eşit. } \\
\text { [10] }\end{array}$ & $\begin{array}{c}\text { qaş-sol } \\
\text { Eşit } \\
{[9]}\end{array}$ & $D_{\text {sağ }}=q_{\text {assssag }} / C s_{a \check{g}}$ & $\mathbf{D}_{\text {sol }}=\mathbf{q}_{\text {as-sol }} / \mathbf{C}_{\text {sol }}$ \\
\hline $\begin{array}{l}\text { A:Emniyet İl } \\
\text { Müdürlüğü }\end{array}$ & 647 & 728 & 80 & 24 & 0 & 2,294 & 1,000 & 24 & 80 & 3,30 & 12,36 \\
\hline $\begin{array}{l}\text { B:Bingöl } \\
\text { Merkez }\end{array}$ & 1388 & 1419 & 332 & 74 & 0 & 2,774 & 1,000 & 74 & 332 & 5,21 & 23,93 \\
\hline $\begin{array}{l}\text { C:Bingöl } \\
\text { Sanayi }\end{array}$ & 1085 & 1142 & 396 & 44 & 0 & 5,127 & 1,000 & 44 & 396 & 3,85 & 36,50 \\
\hline D:Uydukent & 793 & 865 & 105 & 274 & 0 & 0,722 & 0,722 & 198 & 181 & 22,86 & 22,86 \\
\hline
\end{tabular}




\section{Sonuçlar}

Sinyalizasyonlu olarak hizmet veren Düzağaç kavşağının alt geçitli ve alt geçitsiz sinyalizasyonuz turbo dönel kavşak olarak tasarlanması durumunda;

-Sinyalizasyonsuz turbo kavşakların yaygın olarak kullanılmasını sağlamak için modern dönel kavşaklarda olduğu gibi sürücü bilinçlendirilmesinin sağlaması gerektiği;

-Alt geçitli turbo kavşağın kavşağa giriş kollarında sol şerit doygunluğunun alt geçitsize göre ortalama 2 kat, sağ şerit doygunluğunun ise ortalama 5,50 kat azaltmasına karşın, bu kavşağın öncesi ve sonrasında bulunan kavşakları olumsuz yönde etkileneceği:

-Bingöl Sanayi ve Emniyet Müdürlüğü kollarında taşıt trafiğinin alt geçitle sağlanması durumunda, kavşak kollarının sağ şeritlerinde doygunluk yüzdelerinin düşmesine rağmen Bingöl Sanayi, Bingöl Merkez ve Uydukent kollarının sol şeritlerinde ortalama $\% 25$ oranında doygunluk bulunduğu;

-Bingöl Sanayi, Bingöl Merkez ve Uydukent kollarında trafik artışı olması durumunda sol şeritte doygunluk yüzdesi artacağından; Bingöl Sanayi ve Bingöl Merkez kollarının sola dönüş önceliklerine göre üst geçit gerekeceği;

-Uydukent kolunun imar değişiklikleriyle Bingöl Sanayi koluna bağlantısı sağlanarak kavşağın üç kollu sinyalizasyonsuz rotor tipi turbo kavşak yapılması durumunda kapasite ve güvenliğin artırılabileceği;

-Turbo kavşak içerisinde bulunan ayırıcıların karla mücadele sırasında trafik güvenliği ve kapasiteye etkilerinin araştırılması gerektiği tespit edilmiştir.

\section{Kaynaklar}

[1] The 2018 Colorado Department of Transportation (CODOT) Roadway Design Guide, 2018.176-191. https://www.codot.gov/business/designsupport/bulletins_manuals/cdot-roadway-design-guide-2018/dg18-ch10 $(13.12 .2019)$

[2] The Highway Design Manual Guide, 2012. 9: 123.https://www.oregon.gov/ODOT/Engineering/Pages/Hwy-DesignManual.aspx, (16.12.2019).

[3] Karayolları Genel Müdürlüğü, Karayolu Tasarım El Kitabı. 2008.101-151.

[4] Mathew, V, Krishan R, Traffic İntersections, 2007. 1-6

[5] https://nptel. ac.in/content/storage2/courses/105101087/downloads/Lec-39.pdf, (16.01.2020).

[6] https://www.kgm.gov.tr/SiteCollectionDocuments/KGMdocuments/Trafik, (16.01.2020).

[7] Arıkan Öztürk E, Çubuk K, Hatipoğlu S, Aslan D. Modern Dönel Kavşakların Kapasite ve Güvenlik Yönünden İncelenmesi Gazi Üniv. Müh. Mim. Fak. Der., 2007. Cilt 22, No 4. 917-925

[8] Gallelli V, Iuelea T, Vaianaa R. Conversion of a semi-two lanes roundabout into a turbo-roundabout:a performance comparison The 7th International Conference on Ambient Systems, Networks and Technologie ANT, 2016.393-400.

[9] Evaa P, Andreaa K. Case study: capacity characteristics comparison of single-lane roundabout and turbo-roundabouts. Transcom International scientific conference on sustainable, modern and safe transport, 2017. 703- 706.

[10] Skvaina V, Petrua J, Krivdaa V. Turbo roundabouts and their Basic Evaluation at Realized Constructions in Czech Republic. Structural and Physical Aspects of Construction Engineering, 2017. 283-290.

[11] Pilko H, Majcan D. Turbo Roundabaouts: Case Study of Croatşa Transport Logictics Digitial Age, International Scientific Conference Science And Traffic Development, 2018. 221-229.

[12] Bastos A, Luís Vasconcelosb S, Santosa S. Moving from Conventional Roundabouts to Turbo-Roundabouts, 16th Meeting of the EURO Working Group on Transportation, 2013. 2-9.

[13] Bastos A, Santos S, Gaspar M. Turbo-Roundabout Use And Design CITTA, 6th Annual Conference on Planning Research Responsive Transports ForSmart Mobility, 2015. 3-12.

[14] Izadi A, Mirzaiyan D. Comparing Traffic Performances Turbo-Roundabouts and Conventional Roundabout (Case Study), The Turkish Online Journal of Design, Art and Communication TOJDAC, 2016. 2-7.

[15] Guerrieri M, Corriere F. An International Reiviev One and Two Level Innovative Unonventional Intersection and Interchange ARPN, Journal of Engineering and Applied Sciences.2013. 12,1059-1070.

[16] Tollazzi T, Rencelj M. Modern and alternative types of roundabouts-state of the art, The 9th International Conference Environmental Engineering, 2014. 2-6.

[17] Tollazzi T, Mauro R, Guerrieri M, Rencelj, M. Comparative Analysis of Four New Alternative Types of Roundabouts:Turbo, Flower, Target and Four-Flyover Roundabout, Periodica Polytechnica Civil Engineering, 2016. 5160.

[18] Džambas T, Ahac S, Dragčević V. Geometric Dessign of Turbo-Roundabouts. Technical Gazzette, 2017. $309-318$ (Print).

[19] Gredoska N, Bombol K, Nechoska, D. An Evalution of Turbo-Roundabouts Performance:Case Study of the City Ohrid,2016. 2-7.https://trid.trb.org/view/1417701, (16.01.2020).

[20] Ersoy M, Çelikoğlu H.B. Capacity Analysis on Multi Lane Roundabout: An Evalatıon With Higway Capacity Manual 2010 Model, Pamukkale Üniversitesi Mühendislik Bilimleri Dergisi, 2014. 20, 225-226. 
[21] Vasconcelos L, Seco A,Silva A, Abreu T, Comparison of Roundabaout Capacity Models. The IASTED International Conference on Modelling, Simulation and Optimatization 2012. 1-6.

[22] Tumminello M. Calibration of microscopic traffic simulation models for evaluating operation and safety performance at roundabouts, $\mathrm{PhD}$ Thesis, University Palermo, 2018.

[23] Vasconcelas A, Silva A. Capacity of Normal and Turbo-Roundabouts Comparative Analysis, ICE Institution on of Civil Engçneers, 2012. 1-12.

[24] Mallela J, Suri S. Work Zone Road Users Costs Concepts And Aplications, Federal Highwa Administration FHWA, 2011. 28-32.

[25] 2015 yılı devlet yolları trafik hacim haritası (YOGT), kgm.gov.tr Site Collection Documents KGM documents trafik hacim haritasi 2015 hacim haritalari 8. Bölge, (10.12.2019). [26] Kociánová
http://komunikacie.uniza.sk/index.php/communications/article/view/294, (16.12.2019).

Turbo-Roundabouts, 